\title{
Clinical implementation of RNA signatures for pharmacogenomic decision-making
}

This article was published in the following Dove Press journal:

Pharmacogenomics and Personalized Medicine

7 September 2011

Number of times this article has been viewed

\author{
Weihua Tang' \\ Zhiyuan $\mathrm{Hu}^{2}$ \\ Hind Muallem' \\ Margaret L Gulley ${ }^{1,2}$ \\ 'Department of Pathology and \\ Laboratory Medicine, ${ }^{2}$ Lineberger \\ Comprehensive Cancer Center, \\ University of North Carolina at \\ Chapel Hill, North Carolina, NC, USA
}

Correspondence: Margaret L Gulley Department of Pathology and Laboratory Medicine, 913 Brinkhous-Bullitt Building, University of North Carolina

Chapel Hill, NC 27599-7525, USA

$\mathrm{Tel}+\mathrm{I} 9198434595$

Fax +19199666718

Email margaret_gulley@med.unc.edu
Abstract: RNA profiling is increasingly used to predict drug response, dose, or toxicity based on analysis of drug pharmacokinetic or pharmacodynamic pathways. Before implementing multiplexed RNA arrays in clinical practice, validation studies are carried out to demonstrate sufficient evidence of analytic and clinical performance, and to establish an assay protocol with quality assurance measures. Pathologists assure quality by selecting input tissue and by interpreting results in the context of the input tissue as well as the technologies that were used and the clinical setting in which the test was ordered. A strength of RNA profiling is the array-based measurement of tens to thousands of RNAs at once, including redundant tests for critical analytes or pathways to promote confidence in test results. Instrument and reagent manufacturers are crucial for supplying reliable components of the test system. Strategies for quality assurance include careful attention to RNA preservation and quality checks at pertinent steps in the assay protocol, beginning with specimen collection and proceeding through the various phases of transport, processing, storage, analysis, interpretation, and reporting. Specimen quality is checked by probing housekeeping transcripts, while spiked and exogenous controls serve as a check on analytic performance of the test system. Software is required to manipulate abundant array data and present it for interpretation by a laboratory physician who reports results in a manner facilitating therapeutic decision-making. Maintenance of the assay requires periodic documentation of personnel competency and laboratory proficiency. These strategies are shepherding genomic arrays into clinical settings to provide added value to patients and to the larger health care system.

Keywords: RNA, microarray, preanalytic, quality assurance, translational, clinical laboratory

\section{Introduction}

RNA profiling supplements traditional histopathologic, immunologic, cytogenetic, and proteomic means of pharmacogenetic analysis. ${ }^{1}$ By testing tens to thousands of RNAs at once, signatures are generated that reflect abundant and also redundant data on clinical status that could provide added value beyond what is achieved by testing a single analyte. In addition to testing messenger RNA, emerging data on noncoding RNA expression (microRNAs and long noncoding RNAs) represents a new frontier for expression profiling that is likely to inform patient management decisions further. ${ }^{2}$

RNA panels are increasingly being adopted in clinical trials and ultimately, once vetted as reliable and useful, in routine health care settings for decision-making about drug efficacy, to monitor drug action in the intended biochemical pathway or in off-target pathways, or to select optimal dosage. Reliable RNA profiling builds on the same quality assurance principles that have guided laboratory medicine over 
the past few decades. Among the many factors contributing to good outcomes are personnel competency with demonstrated proficiency in achieving expected results, and quality control methods to detect deficiencies in an assay or in the specimen being assayed. Quality of RNA-based profiling has improved over the past decade as a result of several factors, ie, good manufacturing practices making available standardized reagents, controls, and instrumentation, ${ }^{3,4}$ biospecimen research demonstrating best practices to process tissue and to preserve RNA, ${ }^{5,6}$ novel paradigms for quality control to assess analytic performance of the signature rather than of individual components, and software presenting control and patient data to laboratory scientists in a manner facilitating analytic and clinical interpretation. ${ }^{?}$

\section{Assay validation}

Quality assurance parameters are established and refined during validation studies. The main goal of validation work is to demonstrate whether an assay is analytically sound, clinically useful, and of sufficient added value to deem it medically necessary for the care of a defined group of patients. Assay validation guidance published by the College of American Pathologists suggest that studies should be carried out in three parts, ie, a planning phase to devise the assay for its intended use, a data collection phase to gather results on analytic and clinical performance characteristics (eg, sensitivity, specificity), and an implementation phase to transition the assay to the clinical setting once the assay is vetted by the clinical laboratory director. Key steps are summarized in Figure $1 .{ }^{8}$ The validation study defines acceptable specimen types, indications for testing, and a standard operating procedure for performing the test, ${ }^{8-10}$ to include pertinent quality checks and controls. ${ }^{11,12}$

Translational research teams seeking to validate arraybased assays should include technology specialists, clinical trial experts, statisticians, clinicians who will order the test and act on test results, and clinical laboratory technicians who perform the assays and interpret the results. A multidisciplinary development team increases the likelihood of producing an assay that is practical, robust, and sufficiently useful to be incorporated into routine patient care. ${ }^{13}$

A rule of thumb for successful assay design is to use the simplest and safest strategy that meets the clinical objective. For example, Microarray Quality Control (MAQC) project data suggests that a one-color approach yields results equivalent to a two-color approach, while also using fewer reagents and eliminating the potential for bleed-through of fluorochrome from one channel to the other. ${ }^{14-16}$ Thoughtful assay design can help minimize problematic delays that ensue when a critical instrument undergoes repair, when a reagent is on "back-order", or when a patient test must be repeated. This article describes strategies to assure quality of RNA profiling during assay validation and ultimately in day-to-day laboratory medicine practice. This quality assurance work is meant to ward off error and to detect and correct problems when they occur.

\section{Specimen collection, handling, and storage}

Most errors in clinical laboratory assays occur in the preanalytic phase of testing, emphasizing the importance of validating the assay on real-world conditions for specimen collection and transport, processing, and storage prior to analysis. ${ }^{17-21}$

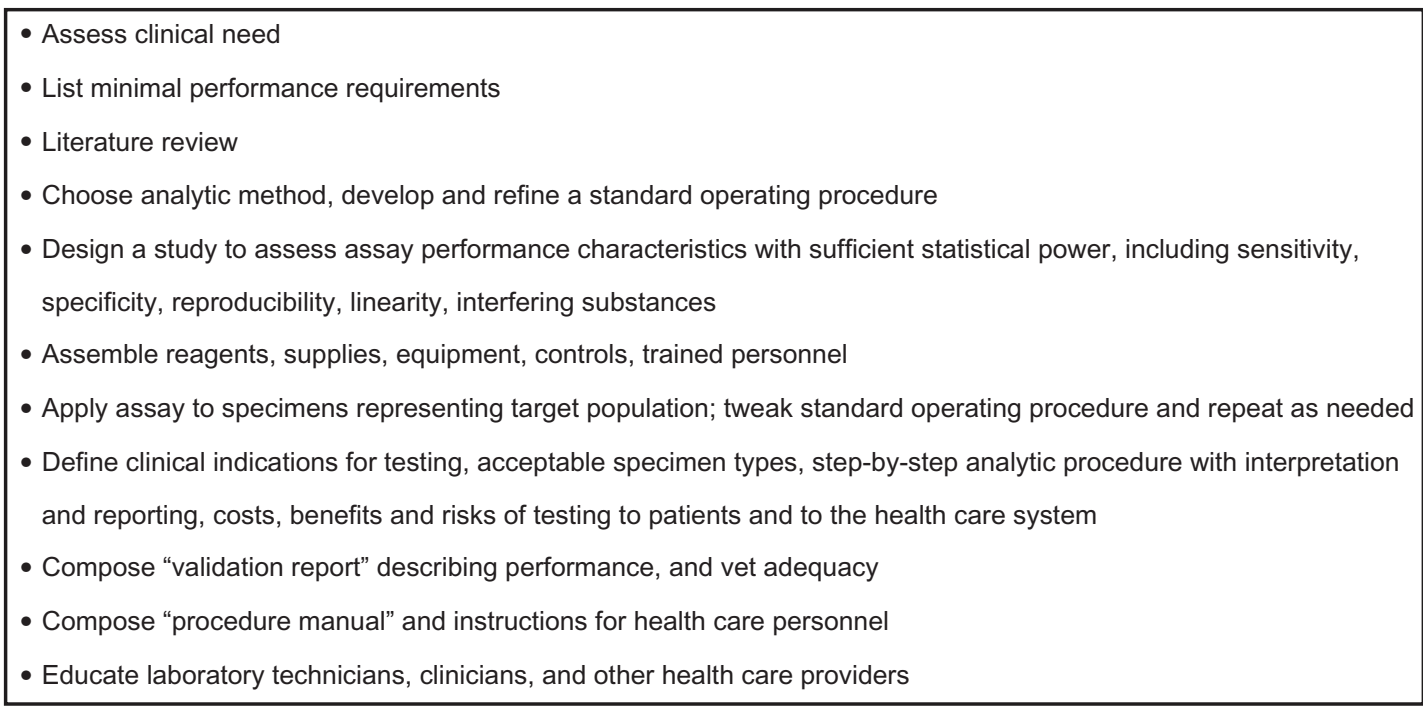

Figure I Steps in validating a laboratory assay. 
According to some reports, the variables confounding RNA signatures can be quite unexpected, such as whether the first or second needle biopsy was tested, ${ }^{22}$ or whether cells were frozen prior to analysis. ${ }^{23,24}$ It is important that validation work address preanalytic variables as a component of the overall efficacy of an assay. ${ }^{6,25-27}$

RNA tends to be unstable, and some transcripts rapidly degrade under adverse collection, storage, or handling conditions. ${ }^{25}$ Stabilization of RNA at the time of whole blood collection is achievable using commercial collection vials, ${ }^{28-33}$ although the benefits of bedside stabilization must be weighed against the downsides that include stocking special blood collection tubes in every applicable blood collection station, and inability to use cell separation technologies to separate subpopulations of white cells or to eliminate unwanted erythrocytes containing abundant globin RNA.

Criteria for acceptance or rejection of specimens should be established during assay validation. ${ }^{34-36}$ In solid tissue, the pathologist who selects tissue for analysis follows a protocol specifying acceptability criteria, such as the minimum proportion of cells that must be malignant in order to generate the relevant tumor-related signatures. ${ }^{37}$ Interpretation of downstream molecular results is done in the context of the input tissue.

Prolonged fixation in formalin causes RNA crosslinking and thwarts RNA extraction. ${ }^{38,39}$ However, formalin fixation also prevents tissue degradation and reduces or eliminates RNase function, permitting such tissues to be profiled successfully after histopathologic examination and storage. ${ }^{40-42}$ Chung et al showed that fixation times of 4-48 hours were reasonable, with 12-24 hours yielding the best RNA in downstream analysis. ${ }^{43}$ For some target RNAs, expression is similar in paraffin blocks and matched frozen tissue, ${ }^{4-47}$ but other RNA targets do not correlate as well. ${ }^{47,48}$

A molecular test is most likely to be adopted if its input specimen type is formalin-fixed, paraffin-embedded tissue, recognizing that variation in the age of a tissue block and its processing variables must also be considered as factors impacting RNA profile. ${ }^{34}$ RNA quality is better in frozen tissue than in formalin fixed tissue; however frozen tissue is not usually saved in clinical settings because of limited tissue volume, upfront uncertainty about the extent of sampling or testing needed to make a traditional histopathologic diagnosis, and the cost of saving and storing tissue by nonstandard methods when most such tissue will not meet the indications for any downstream test.

Acid decalcification, a process typically done to permit histologic sectioning of bony tissues, causes depurination with fragmentation of nucleic acid. Therefore, bone marrow aspirate or clot sections may be more suitable for molecular testing than is a marrow biopsy. Alcohol-based fixatives may yield higher quality RNA than is achieved by formalin fixation, ${ }^{49-51}$ but alternative fixatives are inferior with respect to histologic detail required for a pathologist's microscopic diagnosis and also adverse impact on immunostains that are frequently applied in diagnostic workup of solid tissues. ${ }^{52}$ An important preanalytic step involves assurance that the input tissue is representative of the organ or lesion being evaluated. ${ }^{37}$ Pathologist vetting of tissue acceptability is done by microscopic examination of a stained slide (eg, frozen section, paraffin section, cytologic preparation, or smear). When cell enrichment is required in blood or marrow, flow cytometry or magnetic bead separation is applied..$^{53}$ In solid tissue, cell enrichment is done by macrodissection or microdissection. ${ }^{54-59}$

\section{Controls, quality checks, and limits on their acceptability}

Compared with individual tests, array-based RNA profiles create novel challenges for quality control and for data interpretation. ${ }^{60}$ While traditional single-analyte assays require inclusion of a positive and a negative control in every run, it is clear that microarray tests cannot possibly include a separate control for each of the tens to thousands of target analytes. Thus, a new paradigm of quality control has emerged to accommodate array-based testing by demonstrating that the resulting RNA signature is accurate and reproducible.

Each control is run alongside the patient specimens to generate a result that must fall within previously established limits. Aliquots of residual natural human tissue may be heterogeneous but they are still among the best controls because they closely resemble patient specimens and they can be included in all steps of the assay. However, it is difficult to obtain large amounts of residual patient specimens, so xenograft tissue is a suitable alternative. Stored residual RNA from previously tested blood or tissue specimens is also a suitable control. Cell lines are useful because they can be diluted to test sensitivity and linearity of the test system, and typically these cells or their derivatives are spiked into appropriate matrix so as to mimic patient specimens as closely as possible. A mixture of ten cell lines is used to prepare the Agilent/Stratagene reference RNA that is well characterized in multiple sample exchange studies. ${ }^{57,61,62}$

Controls are designed to test critical aspects of assay performance and to help pinpoint sources of error. Several types of controls are used, ie, "no template" controls evaluate background noise and detect contamination by stray nucleic acid. Exogenous controls are run alongside patient specimens 
in all or in selected stages of the stepwise protocol to check generic assay performance. In an assay with five major outcome groups, it is reasonable to rotate exogenous controls so that any given run contains a control for at least one of the outcome groups (see Figure 2). A failed control would then trigger investigation of all runs since that control last passed muster.

Endogenous controls measure elements that are inherent to a given patient specimen, such as a housekeeping transcript level to address cell viability, cellularity, transport, processing,

A
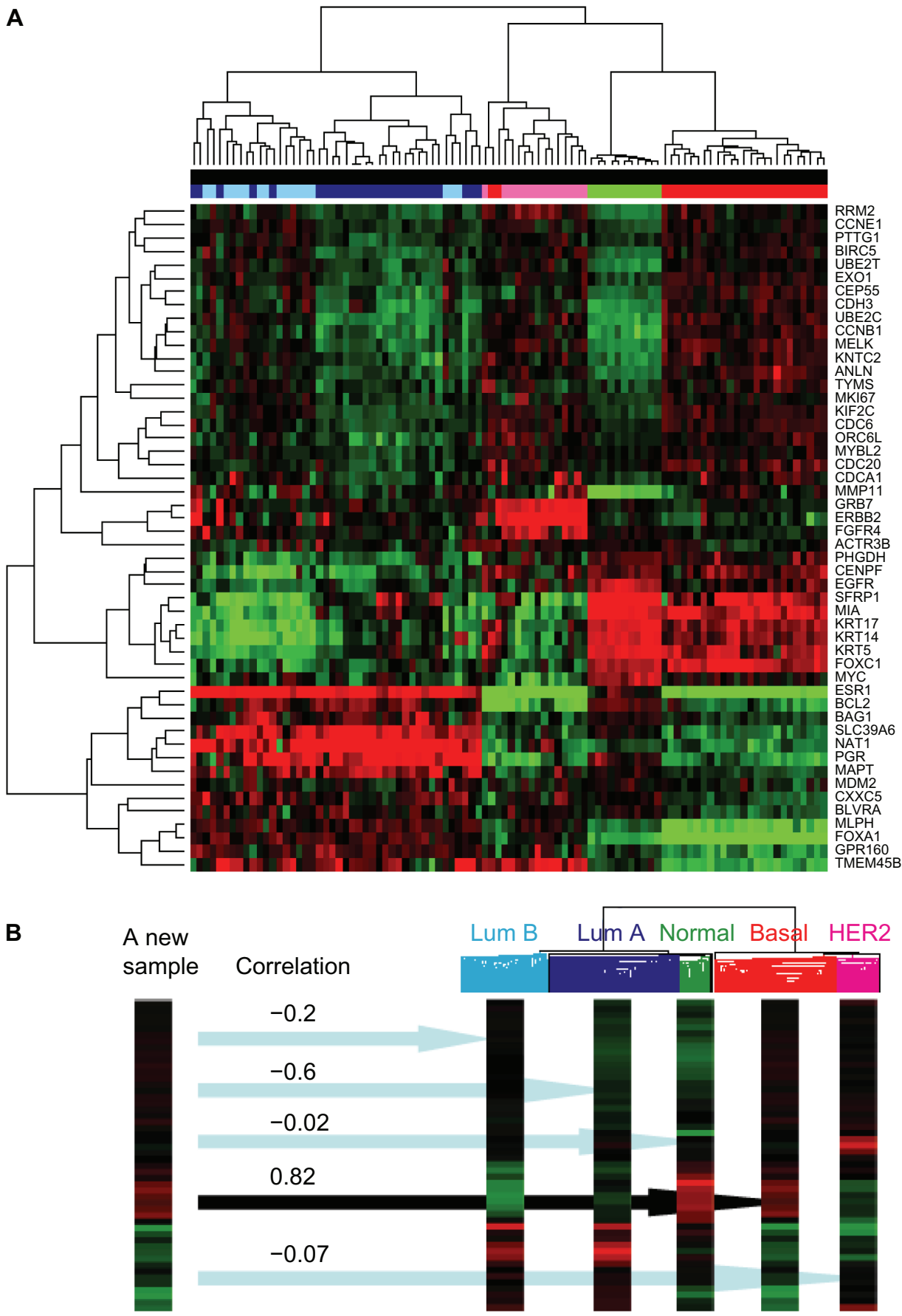

Figure 2 Data interpretation is facilitated by software manipulation of abundant data generated by profiling virtually all approximately 22,000 human genes. (A) An unsupervised clustering algorithm was applied to the full dataset and then to a subset of 50 RNAs listed on the right to generate a heatmap showing patterns of expression in 96 breast cancer tissues. (B) A single sample predictor algorithm helps assign a subtype to a new patient specimen using Spearman's correlation coefficients to estimate certainty of the classification. The expression pattern of a new sample matches the basal subtype of breast cancer most closely, and this result is likely to influence clinical management by virtue of a poor prognosis and lack of response to traditional antineoplastic agents. Typically basal subtype tumors are termed "triple-negative" because they lack immunohistochemical expression of ESRI, PGR, and ERBB2 proteins, so parallel testing of such proteins might serve as a quality assurance measure for the analytic process and also for the clinical categorization of this patient's disease. 
storage, and RNA extraction steps. An RNA signature typically tests for multiple housekeeping transcripts that were selected during validation work for their consistent amount (low, moderate, or high) in the pertinent specimen type. In routine testing, their expression is an indicator of hybridizable RNA that permits rejection of specimens with inadequate RNA quality. ${ }^{45,63}$ Expression levels of one or more housekeepers could serve as a normalizer by which to gauge expression of other transcripts. ${ }^{64-66}$

Spiked controls can evaluate assay performance, at least for those steps of analysis after spiking occurs. Commercial RNA spikes of known sequence (developed by the External RNA Controls Consortium) can be added to each patient specimen either at the time that lysis buffer is added or later when RNA is being prepared for analysis. ${ }^{67-71}$ Their downstream measurement can detect interfering substances such as autofluorescence, heparin anticoagulant, hemoglobin protein or globin RNA, or residual phenol. To track specimens through the many steps of specimen preparation and analysis, combinations of spiked molecules have been proposed as specimen identifiers. $^{72}$

Any control result or quality check falling outside acceptable limits is investigated for the cause of the failure, so that corrective action may be taken when feasible. For example, if spectrophotometry indicates failure of all specimens in a given run, including the control, the extraction procedure is likely to be the culprit. On the other hand, adequacy of the control and all but one of the patients in a given run would indicate which patient specimen to reject or re-extract. Failed hybridization of spiked controls or housekeeping transcripts could help pinpoint whether the flaw lies before or after spiking, thus impacting the action plan in response to the aberrant result. Control results are always documented, as are the actions taken in response to a failure, to promote quality improvement over time.

\section{RNA quality and hybridization reactions}

Automated instruments promote standardization of blood or tissue RNA extractions and also reduce labor costs. The choice of extraction method can impact an RNA signature, ${ }^{73}$ confirming the need to validate the extraction method in concert with the rest of the test system. RNA quantity is often measured using ultraviolet spectrophotometry or fluorimetry, keeping in mind that any DNA interferes with RNA measurement. RNA size may be visualized by electrophoresis, and software algorithms such as the RNA integrity number score have been developed to grade RNA quality. ${ }^{63,66}$ Although delayed processing by up to an hour does not adversely affect the RNA integrity number score, it can affect the RNA signature. . $5,52,74-77^{-7}$

Linear preamplification of RNA permits analysis of very small specimens and also can incorporate a label to permit RNA detection in downstream analysis. ${ }^{45,55,78-81}$ In preparation for the reverse transcription polymerase chain reaction, genomic DNA is usually removed from nucleic acid extracts prior to cDNA preparation. Since aRNA or cDNA preparation can introduce bias, some scientists suggest performing replicates, however the work required to resolve discrepant findings implies that replicate testing will not overcome deficiencies in a poorly designed assay. Clinical grade assays must be robust enough that significant variance in RNA signatures between two patients largely represents biological difference rather than technical error.

Quantitative reverse transcription polymerase chain reaction has a long track record in clinical laboratories, and high throughput quantitative reverse transcription polymerase chain reaction systems are capable of measuring tens to hundreds of RNAs at once $^{82}$ (see Figure 3). Denser array platforms, such as Affymetrix and Agilent microarray systems, are also gaining ground as quality concerns are successfully addressed.,14,83-86 On the horizon are full transcriptome sequencing technologies. ${ }^{85,87}$

Manufacturers are crucial for providing reagents, instruments, and chips to testing laboratories. Clinical laboratories tend to choose manufacturers complying with Food and Drug Administration good manufacturing practices or equivalent International Standardization Organization programs promoting quality and consistency of product across lot numbers. ${ }^{3,4,88,89}$ Manufacturers' products are additionally vetted by the testing laboratory to assure adequate performance for their intended use.

Hybridization reactions are subject to error because of cross-reactivity, interference due to secondary structure or dimerization diminishing intended base pairing, and competition between two or more simultaneous reactions in a single vessel. Many of these concerns are addressed during the validation study conducted prior to clinical implementation. An advantage of array-based assays is the potential to provide redundancy by targeting the same analyte numerous times, such as testing it in different physical quadrants of an array, or targeting several conserved segments of the same transcript using $3^{\prime}, 5^{\prime}$, and intermediary probes. In the virology realm, one could target multiple conserved segments of an RNA viral genome. If a certain biochemical pathway or phenotype is critical, one could target multiple markers signifying that pathway or phenotype. In these scenarios, one capitalizes on the strength of the array in simultaneous analyses. 


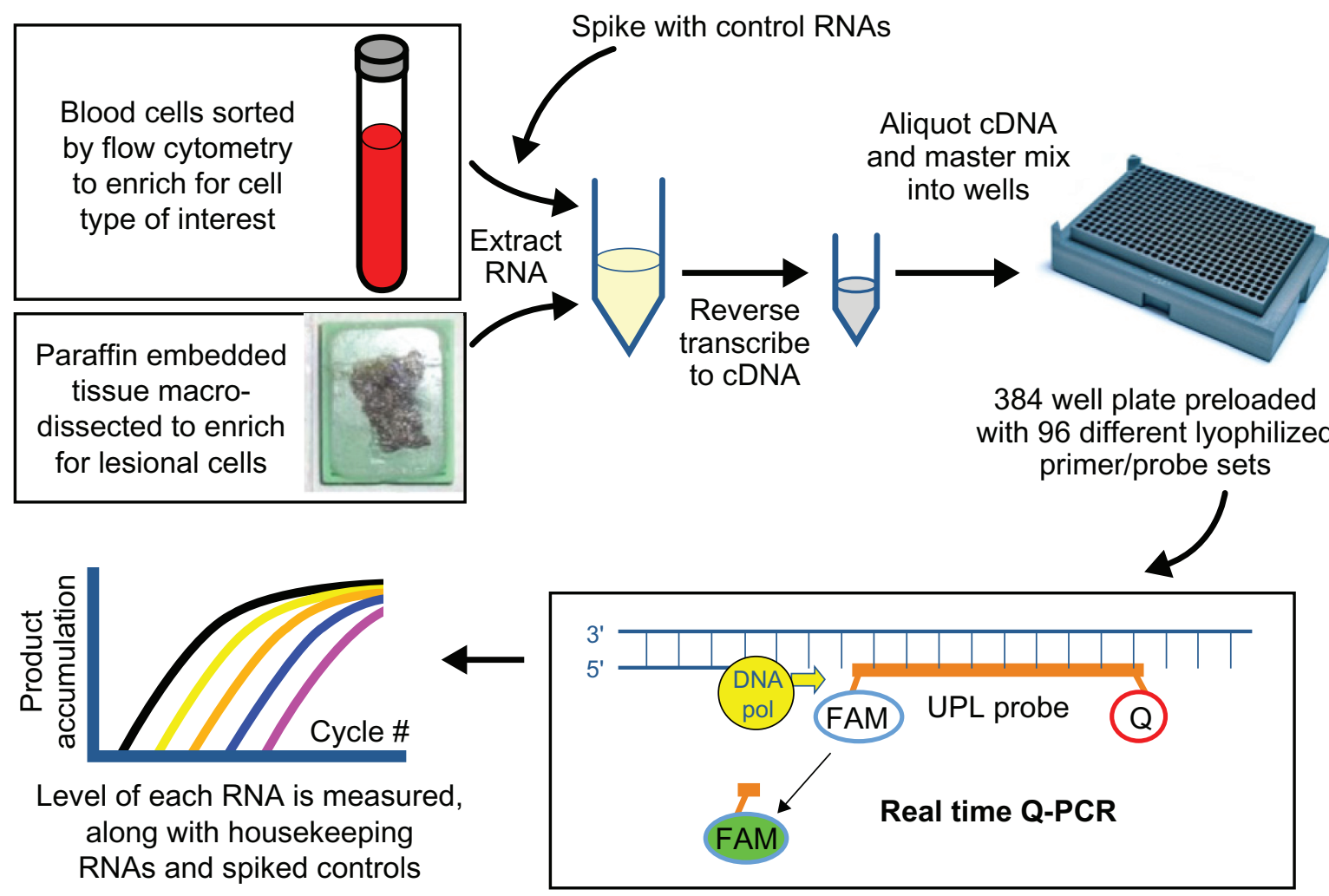

Figure 3 RNA profiling by high throughput quantitative reverse transcription polymerase chain reaction is a complex process requiring multiple quality checks. In this example, cell enrichment procedures are applied to blood or tissue on which a pathologist has confirmed lesional cells, spiked control RNA is added during cell lysis to measure downstream assay performance in the patient specimen, spectrophotometry assures adequate recovery of purified RNA, robotics standardize loading of cDNA and master mix into 384-well Roche RealTime Ready plates preloaded at the factory with lyophilized primers and probes, an internal probe enhances specificity of amplicon measurement beyond that achieved with dye alone, housekeeping RNA measurements reflect the overall adequacy of the specimen and the test system, and decision-support software assists with laboratory physician interpretation of the findings.

\section{Data analysis and interpretation}

Data interpretation is done in the context of a thorough understanding of the technical strengths and weaknesses of the test system, as well as medical issues relevant to the dilemma that the test is meant to solve, building on expertise and prior experience gathered during the validation study and in subsequent clinical practice. Because raw data from massive parallel testing can be quite abundant, software algorithms must present selected data in a manner that facilitates interpretation. ${ }^{7}$ A protocol is followed to generate the dataset for interpretation, such as applying a normalization strategy to adjust for background, or log transformation to facilitate comparison with other samples..$^{64,65,90-93}$ To avoid masking the very biologic variability that is being evaluated, excessive manipulation of data should be avoided. ${ }^{94}$

There are two phases of interpretation, ie, analytic and clinical. Analytic interpretation involves generating a reportable result after first evaluating selected data on the controls and on the patient. Clinical interpretation conveys the significance of the result in patient management. After applying pertinent software algorithms, a package of data, both raw and processed, is assembled for review by the interpreting pathologist or laboratory scientist.

The first step in analytic interpretation is to review results of controls and quality checks. For frozen tissue profiling, example quality checks are listed in Figure 4. For paraffin embedded tissue profiling, Roberts et al used reverse transcription polymerase chain reaction with an $A C T B 3^{\prime}$ to $5^{\prime}$ ratio of $<20$, a $\mathrm{Ct}$ of $<7$ between $A C T B 5^{\prime}$ and the Agilent/Stratagene Universal Reference RNA, and a 28 s rRNA delta $\mathrm{Ct}<15$ to vet RNA before Affymetrix profiling. ${ }^{48}$

Controls of critical importance are developed during validation studies and applied in routine clinical testing. For example, melanoma tissue frequently expresses several melanocyte-specific genes, such as MAGEA1, MITF, MART1 (melan-A), CMM [HMB45], S100, and TYR (tyrosinase), and expression of these factors is a reasonable reflection of the presence of melanocytic cells.

When redundant assays are present on the array, replicates are examined for consistency or to find problematic variations. When redundant pathways or functions are evaluated using 
- The tissue must contain $>30 \%$ malignant cells by frozen section microscopy

- The RNA must have an A260/A280 is $>1.8$ as determined using Nanodrop spectrophotometry and an RNA Integrity Number (score of $>6.5$ as determined using an Agilent Bioanalyzer 2100)

- There must be $>10 \mu \mathrm{g}$ amplified labeled cRNA and its specific activity must be $>8$ pmol Cy 5 per $\mu$ g labeled cRNA by Nanodrop fluorimetry

- Agilent Feature Extraction Software must demonstrate that the scanned results have (A) spike-in RNA is detected with adequate sensitivity, linearity (slope $>0.9, R^{2}>0.85$ ), and replicate reproducibility signified by $B G$ Subsignal $<13$ and processed signal $<6$, (B) uniform spatial distribution with local background of red and green signal $<2 \%$, (C) numbers of features nonuniform $<5 \%$, (D) the dynamic range of expression exceeds five orders of magnitude and there is even distribution of significantly upregulated or downregulated genes across the dynamic range.

Figure 4 Example quality checks on frozen tissue profiled using an Agilent microarray two-color strategy. This is an example; acceptance limits must be established for each application.

separate probes, trends tend to promote confidence in an interpretation, while inconsistent results are a red flag for a technical problem versus patient-specific variation. For example, a highly proliferative tumor is expected to overexpress most of the known proliferation markers on the array.

Criteria for vetting data generated using Affymetrix arrays have been proposed by Staal et al. ${ }^{73}$ These include examining the $3^{\prime}$ to $5^{\prime}$ ratio for selected housekeeping genes ( 1 is ideal, $<3$ is good), assuring the dynamic range of the output signals, checking uniformity across the array chip, and determining if number of expressed RNAs exceeds $25 \%$ of the total.

To categorize the findings in a given patient, a predictive model may be applied that finds patterns across many analytes, as facilitated by a "single sample predictor" algorithm..$^{46,83,95-99}$ The ability to view global patterns of gene expression is a unique strength of expression profiling compared with the discrete testing that characterizes traditional laboratory analysis. An assignment is typically accompanied by a statistic (eg, Spearman's correlation coefficients) representing the strength of the match to one diagnostic category versus each of the others. ${ }^{100}$

A clustering program and a heat map may be generated to display graphically the results of a given patient in a dendrogram alongside the patients in the training and validation sets, to help categorize the patient into pre-established groups based on similarity of expression pattern (see Figure 4). Caution is required when a profile falls at the border between two groups since that patient may not belong to either group. Computer generated scores or predictors should be checked to assure they make sense based on evaluation of pertinent raw data. Assessing the degree of confidence in the result is helpful for downstream clinical interpretation and reporting described below.

\section{Clinical interpretation of results, reporting, and consultations}

Clinical interpretation is done in the context of the clinical indication for which the test was ordered. In this regard, the laboratory test order represents a request for consultation in which the laboratory physician's interpretation answers the question posed by the physician who ordered the test. Even if the end result is a numeric score or a discrete disease classification, it is helpful to interpret the result in light of the input tissue characteristics, pertinent limitations of the assay based on quality checks that were performed during analysis, and the level of confidence in the result. Additional correlative analysis may be done using patient information that is independent of the data generated during testing (eg, age, gender, tumor stage, immunohistochemical, or flow cytometric findings). Most importantly, the impact on clinical decision-making should be described, along with any recommended follow-up. For example, a lymphoblastic leukemia patient whose profile matches the BCR-ABL1 group implies pharmacogenetic response to tyrosine kinase inhibitor therapy, such as desatinib or nilotinib. ${ }^{101,102}$ This classification also suggests the need to confirm that the translocation (p210 versus $\mathrm{p} 190$ breakpoint) is amplifiable by quantitative reverse transcription polymerase chain reaction for purposes of monitoring disease burden during therapy. ${ }^{102}$

Finally, it should be noted that pathologists and other laboratory scientists are accustomed to dealing with unexpected findings. After all, interpreting histologic slides or karyotypes are examples of open-ended procedures for which results may turn out to be completely different from the suspected diagnosis for which the test was ordered. Examination of expression data may yield alternative interpretations that complement or override the objective data generated by a software algorithm. 
Medical judgment is needed to decide which data are reportable, and to describe the clinical significance of relevant findings. Decisions should be based on technical and medical evidence from published literature, validation work, and other reliable sources such as databases of expression profiles on patients of known diagnosis or outcome. ${ }^{103,104}$

The report placed in the patient's medical record contains a written summary of the results and an interpretation that facilitates subsequent decision-making, as recommended in the College of American Pathologists' guidance for molecular test reporting. ${ }^{105}$ Composing a report that is concise yet informative requires technical and medical training, as well as attention to detail. Quality assurance measures might include review of the report for transcription error, review of the raw data and interpretation by a different medical professional, and review of medical records to assure transmission with appropriate formatting. ${ }^{106}$

\section{Data storage and retrospective mining}

Custom-designed and off-the-shelf arrays are available from multiple manufacturers. If an off-the-shelf chip is used, then software can be programmed to mask irrelevant data. United States regulations call for results to be stored for five years in a manner protecting privacy and data integrity. Archival versions of the procedure manual serve to annotate each dataset by linking to the methods used to create the data. It is feasible that the array dataset could be used for one indication at the time of initial testing, and for other indications later (eg, first a diagnostic test, then a prognostic test, then several predictive tests during the course of first-line and second-line therapy selections). The process of revisiting the same patient dataset over and over is analogous to reviewing microscopic slides again in the context of new histopathologic criteria for diagnosis or newly available histochemical assays.

\section{Government regulation and guidance from professional groups}

When laboratory test results are used to guide patient management, even in the context of a clinical trial, then the results must be reliable. In the United States, all such tests are performed in laboratories meeting regulatory standards codified in the Clinical Laboratory Improvement Amendments. Manufacturers of reagents and devices are subject to regulations governing the Food and Drug Administration. Many pharmacogenetic tests have been approved by the Food and Drug Administration, including those targeting RNA of microbial organisms (eg, hepatitis C virus, human immunodeficiency virus, mycobacteria, influenza and other respiratory viruses) and tests for cancer (Agendia Mammaprint, ${ }^{107-109}$ Pathwork Diagnostics Tissue of Origin Test, ${ }^{100}$ and a Veridex assay that is no longer marketed) and transplant rejection (xDx AlloMap). Examples of RNA-based pharmacogenetic tests that were developed and validated in individual testing laboratories include the $B C R$ $A B L 1$ transcript levels and $A B L 1$ mutation status to predict efficacy or dose of tyrosine kinase inhibitor therapy, ${ }^{110}$ and Genomic Health's Oncotype Dx assay for which a recurrence score influences decision-making about use of chemotherapy in breast cancer patients. ${ }^{111,112}$ Pathologists and other physicians in each high complexity testing laboratory are responsible for assuring that tests meet regulatory standards and that appropriate medical consultation is available to clients. ${ }^{113}$ To meet regulatory guidelines in the United States, it is recommended that a physician with molecular subspecialty board certification, document the suitability of the quality control work by signing both the procedure manual and the assay validation report associated with any laboratory developed test.

The MAQC is a Food and Drug Administration initiative addressing the quality of RNA-based microarray expression profiling. ${ }^{114}$ Interlaboratory exchanges of samples and datasets showed that RNA analysis is technically robust as are the bioinformatic prediction models for categorizing array datasets. ${ }^{61,115-118}$ Several clinical professional groups have developed standards for RNA-based testing services, including the laboratory accreditation program of the College of American Pathologists that provides checklists serving as a roadmap for high quality molecular testing, ${ }^{119}$ and the Clinical and Laboratory Standards Institute that has dozens of documents describing standards for validating, implementing, and maintaining molecular assays. Examples include diagnostic nucleic acid microarrays, ${ }^{96}$ use of external RNA controls in gene expression assays, ${ }^{120}$ and verification and validation of multiplex nucleic acid assays. ${ }^{121}$ Helpful guidance is also found in a European guideline for RNA signatures in leuke$\mathrm{mia}^{73}$ and in clinical pharmacogenetic testing guidelines from the National Academy of Clinical Biochemistry. ${ }^{122}$

\section{Personnel competency and laboratory proficiency}

Perhaps the single most important factor in assuring a good outcome is the personnel competency, beginning with the clinician who orders the test and proceeding to those who collect, transport, and handle specimens, followed by those who perform, interpret, and act on test results. 
Meticulous care is required to avoid RNA degradation by using RNAse-free materials, frequently changing gloves and bench covers, and using $10 \%$ bleach or RNaseZap to eliminate extraneous nucleic acid from surfaces. Standard clinical-grade work processes include assuring functionality of each new lot number of reagent prior to its use in patient care, routine preventive maintenance with function checks for each instrument, and competency checks of technical personnel after training and before initiating patient testing, and again on a periodic basis.

Generating an RNA signature requires multistep transfers of a specimen or its derivative which in turn requires painstaking effort to maintain specimen integrity and identification. ${ }^{20,123,124}$ Robotic systems can potentially standardize pipetting and transfer, and barcodes facilitate specimen tracking and labeling. ${ }^{124,125}$ Robots should be programmed to minimize the risk of carryover and contamination.

Proficiency surveys challenge the testing laboratory's performance, educate laboratory personnel, and encourage improvement. ${ }^{126-129}$ Such surveys involve periodic analysis of "unknown" specimens followed by an evaluation of performance against other laboratories doing similar assays. Formal proficiency surveys are offered for some RNA-based pharmacogenetic tests, such as HIV genotyping and PML-RARA translocation. While no formal survey exists for expression profiling, proof of concept that array-based testing is amenable to proficiency testing is shown by the College of American Pathologists' cytogenomic microarray survey which supports interlaboratory comparisons for DNA-based gene copy number analysis. Alternative assessment methods include exchanging samples with laboratory that performs similar tests, or retesting internal samples as if they were unknowns. ${ }^{130}$ The Association for Molecular Pathology $y^{131}$ and the GeneTests website ${ }^{132}$ maintain directories of testing laboratories, and the College of American Pathologists can also help identify a laboratory with whom to exchange specimens. ${ }^{119}$

\section{Conclusion}

RNA profiling is increasingly used to substantiate drug selection or dosage. In the infectious disease realm, molecular analysis of microbial genomes and drug resistance factors can accelerate the time to results and powerfully predict antimicrobial drug efficacy. In the oncology arena, RNA signatures may provide added value for selecting a drug regimen that is likely to overcome the biochemical defect(s) driving tumor cell proliferation. ${ }^{133,134}$ Serial testing is being explored as a way to document the impact of the drug regimen in the intended biochemical pathway or in off-target pathways. ${ }^{135}$

The strategies for quality assurance described herein have shepherded expression profiling into clinical settings. With special attention to RNA quality and data analysis tools, it is likely that robust, accurate, and reproducible RNA-based assays will continue to be developed and implemented. These assays are powerful by virtue of the number of RNAs and pathways that are evaluated, and by redundancy that boosts confidence in the findings.

\section{Acknowledgments}

The authors thank Charles Perou, Greg Ray, Karen Weck, Jessica Booker, Myla Lai-Goldman, and Yan Li of the University of North Carolina at Chapel Hill. This work was supported by the Department of Pathology and Laboratory Medicine, the University Cancer Research Fund, and two grants to the University of North Carolina at Chapel Hill from the National Institutes of Health including a Clinical Translational Science Award and funds from the Alliance for Clinical Trials in Oncology.

\section{Disclosure}

MLG is a consultant for McKesson, Abbott Laboratories, Roche Molecular Diagnostics, and serves on the clinical advisory board of Generation Health.

\section{References}

1. Tumor Analysis Best Practices Working Group. Expression profiling - best practices for data generation and interpretation in clinical trials. Nat Rev Genet. 2004;5(3):229-237.

2. Auer H, Newsom DL, Kornacker K. Expression profiling using Affymetrix GeneChip microarrays. Methods Mol Biol. 2009;509:35-46.

3. Fuscoe JC, Tong W, Shi L. QA/QC issues to aid regulatory acceptance of microarray gene expression data. Environ Mol Mutagen. 2007; 48(5):349-353.

4. Hackett JL, Gutman SI. Introduction to the Food and Drug Administration (FDA) regulatory process. J Proteome Res. 2005;4(4):1110-1113.

5. Imbeaud S, Auffray C. The ' 39 steps' in gene expression profiling: Critical issues and proposed best practices for microarray experiments. Drug Discov Today. 2005;10(17):1175-1182.

6. National Cancer Institute. NCI Best Practices for Biospecimen Resources. Bethesda, MD: United States National Cancer Institute; 2010. Available from: http://www.allirelandnci.com/pdf/NCI_Best_ Practices_060507.pdf. Accessed August 18, 2011.

7. Fox P, Hendler J. Changing the equation on scientific data visualization. Science. 2011;331(6018):705-708.

8. Jennings L, Van Deerlin VM, Gulley ML. Recommended principles and practices for validating clinical molecular pathology tests. Arch Pathol Lab Med. 2009;133(5):743-755.

9. Burd EM. Validation of laboratory-developed molecular assays for infectious diseases. Clin Microbiol Rev. 2010;23(3):550-576.

10. Kohl M. Development and validation of predictive molecular signatures. Curr Mol Med. 2010;10(2):173-179. 
11. Archer KJ, Mas VR, O’Brien TR, Pfeiffer R, Lum NL, Fisher RA. Quality assessment of microarray data in a multicenter study. Diagn Mol Pathol. 2009;18(1):34-43.

12. Bammler T, Beyer RP, Bhattacharya S, et al. Standardizing global gene expression analysis between laboratories and across platforms. Nat Methods. 2005;2(5):351-356.

13. Coyle VM, Johnston PG. Genomic markers for decision making: What is preventing us from using markers? Nat Rev Clin Oncol. 2010;7(2):90-97.

14. Shack S. Gene expression profiling of tissues and cell lines: A dual-color microarray method. Methods Mol Biol. 2011;700:125-143.

15. Oberthuer A, Juraeva D, Li L, et al. Comparison of performance of one-color and two-color gene-expression analyses in predicting clinical endpoints of neuroblastoma patients. Pharmacogenomics J. 2010; 10(4):258-266.

16. Patterson TA, Lobenhofer EK, Fulmer-Smentek SB, et al. Performance comparison of one-color and two-color platforms within the MicroArray Quality Control (MAQC) project. Nat Biotechnol. 2006; 24(9):1140-1150.

17. Holland NT, Smith MT, Eskenazi B, Bastaki M. Biological sample collection and processing for molecular epidemiological studies. Mutat Res. 2003;543(3):217-234.

18. De Cecco L, Musella V, Veneroni S, et al. Impact of biospecimens handling on biomarker research in breast cancer. BMC Cancer. 2009;9:409.

19. Lippi G, Chance JJ, Church S, et al. Preanalytical quality improvement: From dream to reality. Clin Chem Lab Med. 2011;49(7):1113-1126.

20. Plebani M. Errors in clinical laboratories or errors in laboratory medicine? Clin Chem Lab Med. 2006;44(6):750-759.

21. Schmitt M, Mengele K, Schueren E, et al. European Organisation for Research and Treatment of Cancer (EORTC) Pathobiology Group standard operating procedure for the preparation of human tumour tissue extracts suited for the quantitative analysis of tissue-associated biomarkers. Eur J Cancer. 2007;43(5):835-844.

22. Drubin D, Smith JS, Liu W, Zhao W, Chase GA, Clawson GA. Comparison of cryopreservation and standard needle biopsy for gene expression profiling of human breast cancer specimens. Breast Cancer Res Treat. 2005;90(1):93-96.

23. Jochumsen KM, Tan Q, Dahlgaard J, Kruse TA, Mogensen O. RNA quality and gene expression analysis of ovarian tumor tissue undergoing repeated thaw-freezing. Exp Mol Pathol. 2007;82(1):95-102.

24. Vartanian K, Slottke R, Johnstone T, et al. Gene expression profiling of whole blood: Comparison of target preparation methods for accurate and reproducible microarray analysis. BMC Genomics. 2009; 10(1):2

25. Rainen L, Arbique JC, Asthana D, et al. Clinical Laboratory Standards Institute Document MM13-A: Collection, transport, preparation, and storage of specimens for molecular methods approved guideline. Wayne, PA: Clinical and Laboratory Standards Institute; 2005.

26. Leyland-Jones BR, Ambrosone CB, Bartlett J, et al. Recommendations for collection and handling of specimens from group breast cancer clinical trials. J Clin Oncol. 2008;26(34):5638-5644.

27. Moore HM, Kelly AB, Jewell SD, et al. Biospecimen Reporting for Improved Study Quality (BRISQ). J Proteome Res. 2011;10(8): 3429-3438.

28. Williams MA. Stabilizing the code-methods to preserve RNA prove their worth. Biomark Insights. 2010;5:139-143.

29. Asare AL, Kolchinsky SA, Gao Z, et al. Differential gene expression profiles are dependent upon method of peripheral blood collection and RNA isolation. BMC Genomics. 2008;9:474.

30. Matheson LA, Duong TT, Rosenberg AM, Yeung RS. Assessment of sample collection and storage methods for multicenter immunologic research in children. J Immunol Methods. 2008;339(1):82-89.

31. Debey S, Zander T, Brors B, Popov A, Eils R, Schultze JL. A highly standardized, robust, and cost-effective method for genome-wide transcriptome analysis of peripheral blood applicable to large-scale clinical trials. Genomics. 2006;87(5):653-664.
32. Shou J, Dotson C, Qian HR, et al. Optimized blood cell profiling method for genomic biomarker discovery using high-density microarray. Biomarkers. 2005;10(4):310-320.

33. Weber DG, Casjens S, Rozynek P, et al. Assessment of mRNA and microRNA stabilization in peripheral human blood for multicenter studies and biobanks. Biomark Insights. 2010;5:95-102.

34. Hewitt SM, Lewis FA, Cao Y, et al. Tissue handling and specimen preparation in surgical pathology: issues concerning the recovery of nucleic acids from formalin-fixed, paraffin-embedded tissue. Arch Pathol Lab Med. 2008;132(12):1929-1935.

35. Dash A, Maine IP, Varambally S, Shen R, Chinnaiyan AM, Rubin MA. Changes in differential gene expression because of warm ischemia time of radical prostatectomy specimens. Am J Pathol. 2002;161(5): 1743-1748.

36. Ferruelo A, El-Assar M, Lorente JA, et al. Transcriptional profiling and genotyping of degraded nucleic acids from autopsy tissue samples after prolonged formalin fixation times. Int J Clin Exp Pathol. 2011;4(2):156-161.

37. Roepman P, de Koning E, van Leenen D, et al. Dissection of a metastatic gene expression signature into distinct components. Genome Biol. 2006;7(12):R117.

38. Macabeo-Ong M, Ginzinger DG, Dekker N, et al. Effect of duration of fixation on quantitative reverse transcription polymerase chain reaction analyses. Mod Pathol. 2002;15(9):979-987.

39. Chung JY, Hewitt SM. An optimized RNA extraction method from archival formalin-fixed paraffin-embedded tissue. Methods Mol Biol. 2010;611:19-27.

40. Budczies J, Weichert W, Noske A, et al. Genome-wide gene expression profiling of formalin-fixed paraffin-embedded breast cancer core biopsies using microarrays. J Histochem Cytochem. 2011;59(2): 146-157.

41. Saleh A, Zain RB, Hussaini H, et al. Transcriptional profiling of oral squamous cell carcinoma using formalin-fixed paraffin-embedded samples. Oral Oncol. 2010;46(5):379-386.

42. Ton CC, Vartanian N, Chai X, et al. Gene expression array testing of FFPE archival breast tumor samples: An optimized protocol for WG-DASL sample preparation. Breast Cancer Res Treat. 2011; 125(3):879-883.

43. Chung JY, Braunschweig T, Williams R, et al. Factors in tissue handling and processing that impact RNA obtained from formalin-fixed, paraffinembedded tissue. J Histochem Cytochem. 2008;56(11):1033-1042.

44. Parker JS, Mullins M, Cheang MC, et al. Supervised risk predictor of breast cancer based on intrinsic subtypes. J Clin Oncol. 2009;27(8):1160-1167.

45. Abdueva D, Wing M, Schaub B, Triche T, Davicioni E. Quantitative expression profiling in formalin-fixed paraffin-embedded samples by Affymetrix microarrays. J Mol Diagn. 2010;12(4):409-417.

46. Duenwald S, Zhou M, Wang Y, et al. Development of a microarray platform for FFPET profiling: Application to the classification of human tumors. J Transl Med. 2009; 7:65.

47. Mittempergher L, de Ronde JJ, Nieuwland M, et al. Gene expression profiles from formalin fixed paraffin embedded breast cancer tissue are largely comparable to fresh frozen matched tissue. PLoS One. 2011;6(2):e17163.

48. Roberts L, Bowers J, Sensinger K, Lisowski A, Getts R, Anderson MG. Identification of methods for use of formalin-fixed, paraffin-embedded tissue samples in RNA expression profiling. Genomics. 2009;94(5): 341-348.

49. Cox ML, Schray CL, Luster CN, et al. Assessment of fixatives, fixation, and tissue processing on morphology and RNA integrity. Exp Mol Pathol. 2006;80(2):183-191.

50. Cox ML, Eddy SM, Stewart ZS, et al. Investigating fixative-induced changes in RNA quality and utility by microarray analysis. Exp Mol Pathol. 2008;84(2):156-172.

51. Lawson MH, Rassl DM, Cummings NM, et al. Tissue banking of diagnostic lung cancer biopsies for extraction of high quality RNA. J Thorac Oncol. 2010;5(7):956-963. 
52. Medeiros F, Rigl CT, Anderson GG, Becker SH, Halling KC. Tissue handling for genome-wide expression analysis: A review of the issues, evidence, and opportunities. Arch Pathol Lab Med. 2007; 131(12):1805-1816.

53. Hess C, Denkers F, Ossenkoppele G, et al. Gene expression profiling of minimal residual disease in acute myeloid leukaemia by novel multiplex-PCR-based method. Leukemia. 2004;18(12): 1981-1988.

54. Wang S, Wang L, Zhu T, et al. Improvement of tissue preparation for laser capture microdissection: Application for cell type-specific miRNA expression profiling in colorectal tumors. BMC Genomics. 2010;11:163

55. Luttges J, Hahn SA, Heidenblut AM. Manual microdissection combined with antisense RNA-longSAGE for the analysis of limited cell numbers. Methods Mol Biol. 2010;576:135-154.

56. Mojica WD, Sykes DE, Conroy J, Gaile D, Fang X, Nowak N. A comparative analysis of two tissue procurement approaches for the genomic profiling of clinical colorectal cancer samples. Int $J$ Colorectal Dis. 2008;23(11):1089-1098.

57. Mojica WD, Stein L, Hawthorn L. Universal Reference RNA is not a representative normal sample for oligonucleotide microarray studies. Pathol Oncol Res. 2008;14(3):243-51.

58. Mojica WD, Stein L, Hawthorn L. An exfoliation and enrichment strategy results in improved transcriptional profiles when compared to matched formalin fixed samples. BMC Clin Pathol. 2007;7:7.

59. Burgemeister R. Nucleic acids extraction from laser microdissected FFPE tissue sections. Methods Mol Biol. 2011;724:117-129.

60. Shi L, Perkins RG, Fang H, Tong W. Reproducible and reliable microarray results through quality control: Good laboratory proficiency and appropriate data analysis practices are essential. Curr Opin Biotechnol. 2008;19(1):10-18.

61. Shi L, Reid LH, Jones WD, et al. The MicroArray Quality Control (MAQC) project shows inter- and intraplatform reproducibility of gene expression measurements. Nat Biotechnol. 2006;24(9): 1151-1161.

62. Novoradovskaya N, Whitfield ML, Basehore LS, et al. Universal reference RNA as a standard for microarray experiments. BMC Genomics. 2004;5(1):20.

63. Auer H, Lyianarachchi S, Newsom D, Klisovic MI, Marcucci G, Kornacker K. Chipping away at the chip bias: RNA degradation in microarray analysis. Nat Genet. 2003;35(4):292-293.

64. Vandesompele J, De Preter K, Pattyn F, et al. Accurate normalization of real-time quantitative RT-PCR data by geometric averaging of multiple internal control genes. Genome Biol. 2002;3(7):RESEARCH0034.

65. Hellemans J, Mortier G, De Paepe A, Speleman F, Vandesompele J. qBase relative quantification framework and software for management and automated analysis of real-time quantitative PCR data. Genome Biol. 2007;8(2):R19.

66. Becker C, Hammerle-Fickinger A, Riedmaier I, Pfaffl MW. mRNA and microRNA quality control for RT-qPCR analysis. Methods. 2010;50(4):237-243.

67. Devonshire AS, Elaswarapu R, Foy CA. Evaluation of external RNA controls for the standardisation of gene expression biomarker measurements. BMC Genomics. 2010;11:662.

68. Baker SC, Bauer SR, Beyer RP, et al. The external RNA controls consortium: A progress report. Nat Methods. 2005;2(10):731-734.

69. Invitrogen. Available from: www.invitrogen.com. Accessed May 7, 2011.

70. VWR International. Available from: https://ca.vwr.com. Accessed August 25, 2011.

71. Fan X, Fang H, Hong H, Perkins R, Shi L, Tong W. Correlation analysis of external RNA controls reveals its utility for assessment of microarray assay. Anal Biochem. 2009;385(2):203-207.

72. Walter M, Honegger A, Schweizer R, Poths S, Bonin M. Utilization of AFFX spike-in control probes to monitor sample identity throughout Affymetrix GeneChip Array processing. Biotechniques. 2010; 48(5):371-378.
73. Staal FJ, Cario G, Cazzaniga G, et al. Consensus guidelines for microarray gene expression analyses in leukemia from three European leukemia networks. Leukemia. 2006;20(8):1385-1392.

74. Rudloff U, Bhanot U, Gerald W, et al. Biobanking of human pancreas cancer tissue: Impact of ex-vivo procurement times on RNA quality. Ann Surg Oncol. 2010;17(8):2229-2236.

75. Botling J, Micke P. Biobanking of fresh frozen tissue from clinical surgical specimens: Transport logistics, sample selection, and histologic characterization. Methods Mol Biol. 2011;675:299-306.

76. Botling J, Micke P. Fresh frozen tissue: RNA extraction and quality control. Methods Mol Biol. 2011;675:405-413.

77. Botling J, Edlund K, Segersten U, et al. Impact of thawing on RNA integrity and gene expression analysis in fresh frozen tissue. Diagn Mol Pathol. 2009; 18(1):44-52.

78. Vermeulen J, Derveaux S, Lefever S, et al. RNA pre-amplification enables large-scale RT-qPCR gene-expression studies on limiting sample amounts. BMC Res Notes. 2009;2:235.

79. Gonzalez-Roca E, Garcia-Albeniz X, Rodriguez-Mulero S, Gomis RR, Kornacker K, Auer H. Accurate expression profiling of very small cell populations. PLoS One. 2010;5(12):e14418.

80. Corbi FC, Inaoka RJ, Felix RS, et al. Comparative expression of a set of genes to an internal housekeeping control in CDNA amplified and not amplified by PolyAPCR in non-Hodgkin's lymphoma samples obtained from fine-needle aspiration cytology. Diagn Mol Pathol. 2010;19(1):40-44.

81. Ferreira EN, Maschietto M, Silva SD, Brentani H, Carraro DM. Evaluation of quantitative rt-PCR using nonamplified and amplified RNA. Diagn Mol Pathol. 2010;19(1):45-53.

82. Spurgeon SL, Jones RC, Ramakrishnan R. High throughput gene expression measurement with real time PCR in a microfluidic dynamic array PLoS One. 2008;3(2):e1662.

83. Glaves PD, Tugwood JD. Generation and analysis of transcriptomics data. Methods Mol Biol. 2011;691:167-185.

84. Lippa KA, Duewer DL, Salit ML, Game L, Causton HC. Exploring the use of internal and external controls for assessing microarray technical performance. BMC Res Notes. 2010;3:349.

85. Feng L, Liu H, Liu Y, et al. Power of deep sequencing and agilent microarray for gene expression profiling study. Mol Biotechnol. 2010;45(2):101-110.

86. Canales RD, Luo Y, Willey JC, et al. Evaluation of DNA microarray results with quantitative gene expression platforms. Nat Biotechnol. 2006;24(9):1115-1122.

87. Coppée JY. Do DNA microarrays have their future behind them? Microbes Infect. 2008;10(9):1067-1071.

88. Anonymous. Quality System (QS) Regulation/Medical Device Good Manufacturing Practices. Silver Spring, MD: Food and Drug Administration; 2011. Available from: www.fda.gov/MedicalDevices/ DeviceRegulationandGuidance/PostmarketRequirements/QualitySystemsRegulations. Accessed May 7, 2011.

89. International Organization for Standardization. ISO 900 Essentials. Geneva, Switzerland. Available from: www.iso.org/iso/iso_9000_ essentials. Accessed May 7, 2011.

90. Bengtsson M, Ståhlberg A, Rorsman P, Kubista M. Gene expression profiling in single cells from the pancreatic islets of Langerhans reveals lognormal distribution of mRNA levels. Genome Res. 2005;15(10):1388-1392.

91. Ritchie ME, Silver J, Oshlack A, et al. A comparison of background correction methods for two-colour microarrays. Bioinformatics. 2007;23(20):2700-2707.

92. Durbin BP, Rocke DM. Variance-stabilizing transformations for twocolor microarrays. Bioinformatics. 2004;20(5):660-667.

93. Fan J, Niu Y. Selection and validation of normalization methods for c-DNA microarrays using within-array replications. Bioinformatics. 2007;23(18):2391-2398.

94. McMullen PD, Morimoto RI, Amaral LAN. Physically grounded approach for estimating gene expression from microarray data. Proc Natl Acad Sci U S A. 2010;107(31):13690-13695. 
95. Shi L, Campbell G, Jones WD, et al. The MicroArray Quality Control (MAQC)-II study of common practices for the development and validation of microarray-based predictive models. Nat Biotechnol. 2010;28(8):827-838.

96. Hackett JL, Archer JK, Gaigalas AK, et al. Clinical and Laboratory Standards Institute Document MM12-A: Diagnostic nucleic acid microarrays approved guideline. Wayne, PA: Clinical and Laboratory Standards Institute; 2006. Available from: http://www.clsi.org/source/ orders/free/mm12AF.pdf. Accessed August 18, 2011.

97. Hubble J, Demeter J, Jin H, et al. Implementation of GenePattern within the Stanford Microarray Database. Nucleic Acids Res. 2009;37(Database issue):D898-D901.

98. Simon R. Analysis of DNA microarray expression data. Best Pract Res Clin Haematol. 2009;22(2):271-282.

99. Parry RM, Jones W, Stokes TH, et al. k-Nearest neighbor models for microarray gene expression analysis and clinical outcome prediction. Pharmacogenomics J. 2010;10(4):292-309.

100. Monzon FA, Medeiros F, Lyons-Weiler M, Henner WD. Identification of tissue of origin in carcinoma of unknown primary with a microarraybased gene expression test. Diagn Pathol. 2010;5:3.

101. Schultz KR, Bowman WP, Aledo A, et al. Improved early event-free survival with imatinib in Philadelphia chromosome-positive acute lymphoblastic leukemia: A Children's Oncology Group study. J Clin Oncol. 2009;27(31):5175-5181.

102. Izraeli S. Application of genomics for risk stratification of childhood acute lymphoblastic leukaemia: From bench to bedside? $\mathrm{Br} J$ Haematol. 2010;151(2):119-131.

103. Jelier R, Goeman JJ, Hettne KM, Schuemie MJ, den Dunnen JT, t'Hoen PA. Literature-aided interpretation of gene expression data with the weighted global test. Brief Bioinform. February 9, 2011. [Epub ahead of print.]

104. Gudgeon JM, McClain MR, Palomaki GE, Williams MS. Rapid ACCE: Experience with a rapid and structured approach for evaluating genebased testing. Genet Med. 2007;9(7):473-478.

105. Gulley ML, Braziel RM, Halling KC, et al. Clinical laboratory reports in molecular pathology. Arch Pathol Lab Med. 2007;131(6):852-863.

106. Schiff GD, Hasan O, Kim S, et al. Diagnostic error in medicine: Analysis of 583 physician-reported errors. Arch Intern Med. 2009; 169(20):1881-1887.

107. Sotiriou C, Piccart MJ. Taking gene-expression profiling to the clinic: When will molecular signatures become relevant to patient care? Nat Rev Cancer. 2007;7(7):545-553.

108. Evaluation of Genomic Applications in Practice and Prevention (EGAPP) Working Group. Recommendations from the EGAPP Working Group: Can tumor gene expression profiling improve outcomes in patients with breast cancer? Genet Med. 2009;11(1):66-73.

109. Mook S, Bonnefoi H, Pruneri G, et al. Daily clinical practice of fresh tumour tissue freezing and gene expression profiling: Logistics pilot study preceding the MINDACT trial. Eur J Cancer. 2009;45(7):1201-1208.

110. National Comprehensive Cancer Network. NCCN Chronic Myelogenous Leukemia Clinical Practice Guidelines in Oncology (Version 2.2011). 2011. Available from: www.nccn.org. Accessed June 7, 2011.

111. Harris L, Fritsche H, Mennel R, et al. American Society of Clinical Oncology 2007 update of recommendations for the use of tumor markers in breast cancer. J Clin Oncol. 2007;25(33):5287-5212.

112. National Comprehensive Cancer Network. NCCN Breast Cancer Clinical Practice Guidelines in Oncology (Version 2.2011). Available from: www.nccn.org. Accessed June 7, 2011.

113. Rivers PA, Dobalian A, Germinario FA. A review and analysis of the clinical laboratory improvement amendment of 1988: Compliance plans and enforcement policy. Health Care Manage Rev. 2005;30(2):93-102.
114. United States Food and Drug Administration. United States Food and Drug Administration MicroArray Quality Control (MAQC) project. Available from: http://www.fda.gov/ScienceResearch/BioinformaticsTools/MicroarrayQualityControlProject/default.htm. Accessed June 7, 2011.

115. Fan X, Lobenhofer EK, Chen M, et al. Consistency of predictive signature genes and classifiers generated using different microarray platforms. Pharmacogenomics J. 2010;10(4):247-257.

116. Shi W, Bessarabova M, Dosymbekov D, et al. Functional analysis of multiple genomic signatures demonstrates that classification algorithms choose phenotype-related genes. Pharmacogenomics $J$. 2010;10(4):310-323.

117. Tillinghast GW. Microarrays in the clinic. Nat Biotechnol. 2010;28(8): 810-812.

118. Bustin SA, Beaulieu JF, Huggett J, et al. MIQE precis: Practical implementation of minimum standard guidelines for fluorescencebased quantitative real-time PCR experiments. BMC Mol Biol. 2010;11:74

119. College of American Pathologists. Available from: www.cap.org. Accessed May 7, 2011.

120. Warrington JA, Corbisier P, Feilotter H, et al. Clinical Laboratory Standards Institute Document MM16-A: Use of external RNA controls in gene expression assays approved guideline. Wayne, PA: Clinical and Laboratory Standards Institute; 2006.

121. Wilson JA, Zoccoli MA, Jacobson JW, et al. Clinical Laboratory Standards Institute Document MM17-A: Verification and validation of multiplex nucleic acid assays approved guideline. Wayne, PA: Clinical and Laboratory Standards Institute; 2008.

122. Valdes R, Payne D, Linder MW, et al. Guidelines and recommendations for laboratory analysis and application of pharmacogenetics to clinical practice. Washington, DC: National Academy of Clinical Biochemistry; 2007.

123. Szecsi PB, Odum L. Error tracking in a clinical biochemistry laboratory. Clin Chem Lab Med. 2009;47(10):1253-1257.

124. Fabbretti G. Risk management: Correct patient and specimen identification in a surgical pathology laboratory. The experience of Infermi Hospital, Rimini, Italy. Pathologica. 2010;102(3):96-101.

125. Valenstein PN, Alpern GA, Keren DF. Responding to large-scale testing errors. Am J Clin Pathol. 2010;133(3):440-446.

126. Staines H, Garcia-Fernandez L, Pogothata R, Wallace P, MacKay W, Van Loon A. Monitoring performance of nucleic acid-based diagnostic measurement system users by EQA. Accreditation and Quality Assurance: Journal for Quality, Comparability and Reliability in Chemical Measurement. 2009;14(5):243-252.

127. Tholen DW BL, Boone DJ, Cooper WG, et al. Clinical Laboratory Standards Institute document GP27-A2: Using proficiency testing to improve the clinical laboratory approved guideline. 2nd ed. Wayne, PA: Clinical and Laboratory Standards Institute; 2007.

128. Madej RM, Cao Z, Dolinger DL, Hall L, Neuwald P, Williams LO. Clinical and Laboratory Standards Institute Document MM14-A: Proficiency testing (external quality assessment) for molecular methods approved guideline. Wayne, PA: Clinical and Laboratory Standards Institute; 2005.

129. Quality Control for Molecular Diagnostics. Available from: www. qcmd.org. Accessed May 7, 2011

130. Sarewitz SJ, George H, Miller WG, Tholen DW, Valenstein PN. Clinical Laboratory Standards Institute Document GP29-A2: Assessment of laboratory tests when proficiency testing is not available approved guideline. 2nd ed. Wayne, PA: Clinical and Laboratory Standards Institute; 2008

131. Association for Molecular Pathology. AMP Test Directory. Available from: www.amptestdirectory.org. Accessed May 7, 2011. 
132. National Center for Biotechnology Information. GeneTests. Available from: www.genetests.org. Accessed May 7, 2011.

133. Bild AH, Parker JS, Gustafson AM, et al. An integration of complementary strategies for gene-expression analysis to reveal novel therapeutic opportunities for breast cancer. Breast Cancer Res. 2009;11(4):R55.
134. Hu Z, Fan C, Livasy C, et al. A compact VEGF signature associated with distant metastases and poor outcomes. BMC Med. 2009;7:9.

135. Huang J, Shi W, Zhang J, et al. Genomic indicators in the blood predict drug-induced liver injury. Pharmacogenomics J. 2010;10(4): 267-277.

\section{Publish your work in this journal}

Pharmacogenomics and Personalized Medicine is an international, peerreviewed, open access journal characterizing the influence of genotype on pharmacology leading to the development of personalized treatment programs and individualized drug selection for improved safety, efficacy and sustainability. This journal is indexed on the American Chemical
Society's Chemical Abstracts Service (CAS). The manuscript management system is completely online and includes a very quick and fair peer-review system, which is all easy to use. Visit http://www.dovepress. $\mathrm{com} /$ testimonials.php to read real quotes from published authors.

Submit your manuscript here: http://www.dovepress.com/pharmacogenomics-and-personalized-medicine-journal 